\title{
Bioequivalence of Canagliflozin/Metformin Immediate Release Fixed- Dose Combination Tablets Compared with Concomitant Administration of Single Components of Canagliflozin and Metformin in Healthy Fed Participants
}

\section{Devineni $\mathbf{D}^{1 *}$, Curtin $\mathbf{C R}^{1}$, Ariyawansa $\mathrm{J}^{1}$, Weiner $\mathbf{S}^{1}$, Stieltjes $\mathrm{H}^{2}$, Vaccaro $\mathbf{N}^{3}$, Shalayda $\mathbf{K}^{1}$, Murphy $\mathrm{J}^{1}$, DiProspero $\mathrm{NA}^{1}$ and Wajs $\mathrm{E}^{2}$}

1 Janssen Research and Development, LLC, Raritan, NJ, USA

${ }^{2}$ Janssen Research and Development, a division of Janssen Pharmaceutica NV, Beerse, Belgium

${ }^{3}$ Janssen Research and Development, LLC, San Diego, CA, USA

\begin{abstract}
Background: A fixed-dose combination (FDC) tablet formulation of canagliflozin, a selective inhibitor of sodium glucose co-transporter 2 (SGLT2), and metformin can potentially provide complimentary mechanism of action to improve glycemic control in adults with type 2 diabetes mellitus.

Objectives: To assess the bioequivalence of immediate release (IR) FDC tablets containing canagliflozin and metformin relative to co-administration of individual tablets of IR canagliflozin and metformin in healthy fed participants.

Methods: The six studies were randomized, open-label, single-center, single-dose, 2-treatment, 2-period crossover trials conducted in healthy male and female participants under fed conditions. Pharmacokinetics of canagliflozin and metformin were investigated following administration of 2 canagliflozin/metformin IR FDC tablets (test) at $50 \mathrm{mg} / 500 \mathrm{mg}, 50 \mathrm{mg} / 850 \mathrm{mg}, 50 \mathrm{mg} / 1,000 \mathrm{mg}, 150 \mathrm{mg} / 500 \mathrm{mg}, 150 \mathrm{mg} / 850 \mathrm{mg}$, or $150 \mathrm{mg} / 1,000 \mathrm{mg}$ compared with co-administration of equivalent doses of single-component IR tablets (reference).

Results: Across the six studies, a total of 64 to 83 participants were randomized to each treatment sequence and 57 to 68 were analyzed. The median $\mathrm{t}_{\text {mix }}$, mean $\mathrm{t}_{12}$, and mean plasma canagliflozin and metformin concentrationtime profiles were similar after administration of IR FDC and individual components.Bioequivalence criteria for the FDC with respect to $A \cup C_{\infty}, A \cup C_{\text {last }}$, andC $C_{\max }$ of both canagliflozin and metformin met the $90 \% \mathrm{Cl}$ for the test-toreference geometric mean ratios of these parameters and were contained within the bioequivalence limits of $80 \%$ to $125 \%$.Both treatments were well-tolerated with similar adverse events and the most common were gastrointestinal events generally attributed to metformin.
\end{abstract}

Conclusions: When administered as IR FDC tablets or individual component IR tablets, the pharmacokinetics of canagliflozin and metformin across six dose levels were bioequivalent and were well-tolerated.

Keywords: Bioequivalence; Canagliflozin; Metformin; Fixed-dose combination; Pharmacokinetics

Abbreviations: FDC: fixed-dose combination; SGLT2: sodium glucose co-transporter 2; IR: immediate release; $\mathrm{AUC}_{\infty}$ : area under the plasma concentration-time curve from time 0 to infinite time; $\mathrm{AUC}_{\text {last }}$ : area under the plasma concentration-time curve from time 0 to the time of the last quantifiable concentration; $\mathrm{C}_{\max }$ : maximum observed plasma concentration; $t_{\max }$ : maximum observed plasma concentration; $\mathrm{t}_{1 / 2}$ : terminal elimination half-life; CI: confidence interval; CV: coefficient of variation; GMR: geometric mean ratio; T2DM: type 2 diabetes mellitus; QD: once daily; DPP-4:dipeptidyl peptidase-4 inhibitors; PPAR: peroxisome proliferator-activated receptor agonists; K2EDTA:dipotassium ethylenediaminetetraacetic acid; LC-MS/MS: liquid chromatography-tandem mass spectrometry; MRM: multiple reaction monitoring; IS: internal standard; ISR: incurred sample reproducibility; BMI: body mass index; TEAE: treatment-emergent adverse event; ECG: electrocardiograms

\section{Introduction}

Type 2 diabetes mellitus (T2DM) is the most prevalent metabolic disease worldwide. Inadequate management and control of hyperglycemia in patients with T2DM may lead to risk of developing complications over long term due to chronic and progressive nature of the disease arising from pathophysiology of beta-cell dysfunction, insulin resistance and increased hepatic glucose output. Patients with T2DM often require a combination of therapeutic agents in order to achieve glycemic control over the long term [1-5]. Recent position statement by the American Diabetes Association and the European Association for the Study of Diabetes has recommended that for patients who are inadequately controlled with metformin, additional antihyperglycemic agents be used that have complimentary mechanisms of action [2].

Metformin is the most commonly prescribed oral antidiabetic agent recommended as a first-line therapy in management of T2DM whose

*Corresponding author: Dr. DamayanthiDevineni, Janssen Research and
Development, LLC,920 Route 202, Raritan, NJ 08869, USA, Tel: (908) 927-4217; Fax: (908) 927-2573; E-mail: ddevinen@its.jnj.com

Received July 08, 2014; Accepted September 30, 2014; Published October 11 2014

Citation: Devineni D, Curtin CR, Ariyawansa J, Weiner S, Stieltjes $\mathrm{H}$, et al. (2014) Bioequivalence of Canagliflozin/Metformin Immediate Release FixedDose Combination Tablets Compared with Concomitant Administration of Single Components of Canagliflozin and Metformin in Healthy Fed Participants. J Bioequiv Availab 6: 164-173. doi:10.4172/jbb.1000199

Copyright: (c) 2014 Devineni D, et al. This is an open-access article distributed under the terms of the Creative Commons Attribution License, which permits unrestricted use, distribution, and reproduction in any medium, provided the original author and source are credited. 
Citation: Devineni D, Curtin CR, Ariyawansa J, Weiner S, Stieltjes H, et al. (2014) Bioequivalence of Canagliflozin/Metformin Immediate Release Fixed-Dose Combination Tablets Compared with Concomitant Administration of Single Components of Canagliflozin and Metformin in Healthy Fed Participants. J Bioequiv Availab 6: 164-173. doi:10.4172/jbb.1000199

hyperglycemia is not satisfactorily managed by diet alone. Metformin decreases hepatic glucose production, decreases intestinal absorption of glucose, and improves insulin sensitivity by increasing peripheral glucose uptake and utilization [6,7]. Metformin immediate release (IR) tablets are available at 500, 850, and 1,000 $\mathrm{mg}$ strengths of metformin hydrochloride $(\mathrm{HCl})$ and are administered 2 or 3 times daily up to a maximum recommended daily dose of $2,550 \mathrm{mg}$ in adults $[8,9]$.

Canagliflozin (Invokana; Janssen Pharmaceuticals, Inc.) belongs to a novel class of orally active inhibitors of renal sodium glucose cotransporter 2 (SGLT2) that decrease extent of glucose reabsorption from the proximal tubules of the kidney, thereby increasing urinary glucose excretion (UGE) and decreasing plasma glucose levels in patients with hyperglycemia [10-20]. Canagliflozin is approved as an adjunct to diet and exercise to improve glycemic control in adults with T2DM in numerous countries worldwide. The recommended dose of canagliflozin is 100 or $300 \mathrm{mg}$ once daily (QD) [21-23].

Canagliflozin's novel and distinct mechanism of action from other classes of oral antidiabetic agents such as dipeptidyl peptidase- 4 inhibitors (DPP-4), sulfonylureas, and peroxisome proliferatoractivated receptor agonists (PPAR) makes canagliflozin an ideal candidate for add-on combination therapy with metformin and other antidiabetic agents. In Phase 3 studies of canagliflozin (100 and $300 \mathrm{mg}$ QD) in participants with T2DM who were inadequately controlled with metformin monotherapy, or dual therapy with metformin plus sulphonylurea, or metformin plus pioglitazone, the addition of canagliflozin significantly improved glycemic control and was associated with a low incidence of hypoglycaemia and clinically meaningful weight loss at all doses [24-26].

A combined formulation consisting of both metformin and canagliflozin in a single tablet would potentially offer increased patient convenience and subsequent potential for increased therapy compliance $[27,28]$. Vokanamet ${ }^{\mathrm{TM}}$ (Janssen Pharmaceuticals, Inc.) is an immediate release (IR) fixed-dose combination (FDC) tablet of canagliflozin (50 or $150 \mathrm{mg})$ and metformin $(500,850$, or $1,000 \mathrm{mg})$ that has received regulatory approval in the European Union for the treatment of adults with T2DM to improve glycemic control in patients not adequately controlled on their maximally tolerated doses of metformin alone or combined with other glucose lowering medicinal products including insulin, and patients already treated with combination of canagliflozin and metformin as separate IR tablets [29].

Differences in the formulation of a fixed-dose combination (FDC) tablet relative to individual tablets may affect performance of the FDC tablet in the gastrointestinal tract and hence influence bioavailability of its components [30]. Six dose strengths of canagliflozin/metformin IR FDC tablets consisting of canagliflozin at 50 or $150 \mathrm{mg}$ and metformin at 500,850 , or $1,000 \mathrm{mg}$ were evaluated in six separate single-dose Phase 1 bioequivalence studies. The studies evaluated bioequivalence of canagliflozin/metformin IR FDC tablets compared to co-administration of canagliflozin and metformin individual singlecomponent IR tablets in healthy fed participants. The FDC tablets at different dose strengths were based on the same qualitative composition and the same manufacturing process.

\section{Participants and Methods}

\section{Study population}

Men and women with a minimum age of 18 (or 19 in Studies 1, 2, 6; minimum age of consent for the research center) to 55 years who were considered healthy based on medical history, physical examination, and clinical laboratory evaluations, were enrolled in these studies. Participants had a body mass index (BMI) of 18.5 to $30 \mathrm{~kg} / \mathrm{m}^{2}$, a body weight $\geq 50 \mathrm{~kg}$, and blood pressure between 90 and $140 \mathrm{mmHg}$. Pregnant or breast feeding women were excluded from the study. Participants with history of drug or alcohol abuse were excluded. Participants refrained from taking any over-the-counter or prescription medications (with the exception of acetaminophen, oral contraceptives, and hormonal replacement therapy) for at least 14 days prior to first drug administration and throughout the study.

The protocol for each of the studies was approved by an Institutional Review Board at each study site. The studies were conducted in accordance with the ethical principles originating in the Declaration of Helsinki and in accordance with International Conference on Harmonisation (ICH) Good Clinical Practice guidelines, applicable regulatory requirements, and in compliance with the protocol. All participants provided written informed consent to participate in the studies.

\section{Study design}

All six studies were randomized, open-label, single-center, singledose, 2-treatment, 2-period crossover trials consisting of 3 phases: a screening phase of approximately 3 weeks (day-22 through day-2); a treatment phase up to 20 days (including a washout period of 10 to 15 days between day 1 of each of treatment period), and a follow-up phase 7-10 days after day 4 of period 2 or at early withdrawal. The total planned duration of the study for each participant was approximately 7 weeks.

During the treatment phase, eligible participants were admitted to the clinical research center on day-1 of each treatment period. On day 1 of treatment period 1 , all participants were randomized (1:1) to receive either Treatment $A$ in period 1 , followed by Treatment $B$ in period 2 (sequence $A B$ ) or vice versa (sequence $B A$ ). For Treatment $B$ (test), participants received 2 tablets of to-be-marketed canagliflozin/ metformin IR FDC tablets of $50 \mathrm{mg} / 500 \mathrm{mg}, 50 \mathrm{mg} / 850 \mathrm{mg}$, or 50 $\mathrm{mg} / 1,000 \mathrm{mg}$ in Studies 1, 2 and 3, respectively; and 2 tablets of 150 $\mathrm{mg} / 500 \mathrm{mg}, 150 \mathrm{mg} / 850 \mathrm{mg}$, or $150 \mathrm{mg} / 1,000 \mathrm{mg}$ in Studies 4,5 , and 6, respectively. For Treatment A (reference), participants received equivalent doses of single component tablets of to-be-marketed canagliflozin and metformin IR: 1 canagliflozin tablet of $100 \mathrm{mg}$ (Studies 1, 2, and 3) or $300 \mathrm{mg}$ (Studies 4, 5, and 6), and 2 metformin tablets of $500 \mathrm{mg}$ (Studies 1, 4), $850 \mathrm{mg}$ (Studies 2, 5) or 1,000 mg (Studies 3,6). Metformin IR tablets were supplied as commercially available Glucophage IR tablets sourced from United States $[8,9]$. (ClinicalTrials.gov identifiers: Study 1: NCT01508195; Study 2: NCT01463774; Study 3: NCT01454622; Study 4: NCT01508182; Study 5: NCT01518712, Study 6: NCT01463228).

Following an overnight fast of at least 10 hours, study drug administration occurred at approximately the same time each morning under fed conditions. Fluids were restricted beginning 1 hour before and lasting until 1 hour after dosing, except for the milk with breakfast and water administered with the study drug. Approximately 30 minutes before study drug administration, participants were given a standardized high-fat breakfast consisting of 2 strips of fried bacon, 2 eggs fried in butter, 4 ounces ( 120 gram) hash brown potatoes, 2 buttered pieces of white toast, and $240 \mathrm{~mL}$ whole milk [30].Participants were to consume the entire meal in 30 minutes. Study drug was administered 30 minutes after the start of the meal with $240 \mathrm{~mL}$ of noncarbonated water. Study drug was to be swallowed whole. No additional food was allowed for at least 4 hours postdose. 
Citation: Devineni D, Curtin CR, Ariyawansa J, Weiner S, Stieltjes H, et al. (2014) Bioequivalence of Canagliflozin/Metformin Immediate Release Fixed-Dose Combination Tablets Compared with Concomitant Administration of Single Components of Canagliflozin and Metformin in Healthy Fed Participants. J Bioequiv Availab 6: 164-173. doi:10.4172/jbb.1000199

\section{Pharmacokinetic evaluations}

Sample collection: Venous blood samples $(2 \mathrm{~mL}$ for canagliflozin and $2 \mathrm{~mL}$ for metformin) for determination of canagliflozin and metformin plasma concentrations were collected at predose, and at $0.5,1,1.5,2,3,4,6,8,10,12,16,24,48$ (canagliflozin only) and 72 (canagliflozin only) hours postdose on day 1 of each treatment period (for all studies) through an indwelling catheter into collection tubes containing dipotassium ethylenediaminetetraacetic acid (K.EDTA) as anticoagulant. The samples were centrifuged at room temperature (10 minutes at 1,300 g) to obtain plasma. All plasma samples were stored at or below $-20^{\circ} \mathrm{C}$ until transferred to a bioanalytical facility.

Analytical methods: $\mathrm{K}_{2}$ EDTA plasma canagliflozin concentrations were determined with ${ }^{13} \mathrm{C}_{6}$-canagliflozin as internal standard (IS) using validated liquid chromatography-tandem mass spectrometry (LC-MS/ MS) method at PRA (Assen, The Netherlands). The HPLC system consisted of a Shimadzu LC-10Advp pump (PRA) with Shimadzu SILHTC autosampler (Shimadzu Corporation, Japan). An API4000 mass spectrometer with a Turbo-Ionspray ${ }^{\mathrm{TM}}$ Interface (AB SCIEX, MA, USA) in the positive ion mode was used for MS determination. Multiple reaction monitoring (MRM) transitions were $\mathrm{m} / \mathrm{z} \quad 462.1 \rightarrow 267.0$ and $468.1 \rightarrow 273.0$ for canagliflozin and IS, respectively. The method for canagliflozin plasma determination used a liquid-liquid extraction with tert-butylmethylether, followed by chromatography with $30 \%$ ammonium acetate $(0.01 \mathrm{M})$ and $70 \%$ methanol as the mobile phase. The flow rate was $0.25 \mathrm{~mL} / \mathrm{min}$ on a Waters XBridge ${ }^{\mathrm{TM}} \mathrm{C} 18$ column ( $5 \mathrm{~cm} \times 2.1 \mathrm{~mm}, 3.5-\mu \mathrm{m}$ particle size), kept at $30^{\circ} \mathrm{C}$. The validated quantification range was 5.0 to $5,000 \mathrm{ng} / \mathrm{mL}$.

$\mathrm{K}_{2}$ EDTA plasma metformin concentrations were determined with ${ }^{2} \mathrm{H}_{6}$-metformin as IS. The same LC-MS/MS system as for the canagliflozin assay was used, but with an API3000 mass spectrometer, also in the positive ion mode. MRM transitions were $\mathrm{m} / \mathrm{z} 130.1 \rightarrow 70.9$ and $136.0 \rightarrow 77.0$ for metformin and metformin IS, respectively. The sample preparation consisted of a protein precipitation with acidic (formic acid) acetonitrile, followed by gradient ion-pair chromatography with $0.02 \mathrm{M}$ hexafluorobutyric acid in $0.01 \mathrm{M}$ ammonium acetate (A) and acetonitrile (B), from $5 \%$ to $27.5 \%$ B in 3 minutes. The flow rate was $0.3 \mathrm{~mL} / \mathrm{min}$ over a Waters XBridge ${ }^{\mathrm{TM}}$ Shield RP18 column $(5 \mathrm{~cm} 2.1$ $\mathrm{mm}, 3.5-\mu \mathrm{m}$ particle size), kept at $40^{\circ} \mathrm{C}$. The validated quantification range was 5.0 to $2,500 \mathrm{ng} / \mathrm{mL}$.

The validation was performed according to Food and Drug Administration (FDA) guidance for bioanalysis [31,32]. This included within- and between-run precision and accuracy, selectivity, matrix effect, recovery, incurred sample reproducibility (ISR) and stability (blood, plasma, processed sample). All validation results were within predefined acceptance criteria. The storage period between sample collection and analysis was covered by the available long-term stability data for the analytes in the presence of the other analyte (for canagliflozin 762 days and for metformin 190 days at $-20^{\circ} \mathrm{C}$ ).

Pharmacokinetic analyses: The following plasma pharmacokinetic parameters were determined for canagliflozin and metformin based on the individual subject plasma concentration-time data, using actual sampling times via non-compartmental methods using validated WinNonlin software Version 5.2.1 (Pharsight Corporation, Mountain View, CA): maximum observed plasma concentration $\left(\mathrm{C}_{\max }\right)$, time to reach maximum observed plasma concentration $\left(t_{\max }\right)$, terminal elimination half-life $\left(t_{1 / 2}\right)$, area under the plasma concentration-time curve from time 0 to infinite time (AUC $\infty$ ), and area under the plasma concentration-time curve from time 0 to the time of the last quantifiable concentration $\left(\mathrm{AUC}_{\text {last }}\right)$.

Safety Assessments: In all studies, safety evaluations were based upon the type, incidence, and severity of treatment-emergent adverse events (TEAEs) reported throughout the study, and on clinical laboratory tests, vital sign measurements, physical examinations, and 12-lead electrocardiograms (ECG) assessed at pre-defined time points.

\section{Statistical analyses}

Sample size: In all studies, the intra-participant coefficient of variation $(\mathrm{CV})$ of $\mathrm{AUC}_{\text {last }}, \mathrm{AUC}_{\infty}$, and $\mathrm{C}_{\max }$ was estimated to be $\leq 23 \%$. Using an estimated intra-participant $\mathrm{CV}$ of $23 \%$ and a $5 \%$ level of significance, a sample size of 56 participants was considered to be sufficient to conclude bioequivalence between 2 FDC tablets and the individual components at equal doses with an overall power of $80 \%$ (90\% power for the individual components), when the true ratio of the treatment means equalled $91 \%$ or $110 \%$. For each study, planned enrollment was 64 participants with the option of enrolling additional participants if needed to ensure that at least 56 participants completed the study.

Statistical comparison: The primary pharmacokinetic parameters of interest for the statistical analysis were the log-transformed canagliflozin and metformin $\mathrm{AUC}_{\infty}, \mathrm{AUC}_{\text {last }}$ and $\mathrm{C}_{\max }$ values.

Only the data from participants who completed all required openlabel assessments, up to and including day 4 of treatment period 2, were included in the statistical analysis. If one of the pharmacokinetic parameters of interest was not estimable for a given participant in one or more periods, that participant's data was not included in the statistical analysis of that particular pharmacokinetic parameter.

A mixed-effect analysis of variance model that included treatment, period, and treatment sequence as fixed effects, and participant as a random effect, was used to estimate the least squares means and intraparticipant variance. Using these estimated least squares means and intra-participant variance, the point estimates and $90 \%$ confidence intervals (CIs) for the difference in means on a log scale between Treatment B (test) and A (reference) were constructed. The limits of the CIs were retransformed using antilogarithms to obtain the $90 \%$ CIs for the ratios of the geometric mean $\mathrm{AUC}_{\infty}, \mathrm{AUC}_{\text {last }}$, and $\mathrm{C}_{\max }$ of the test to reference treatments $(\mathrm{B} / \mathrm{A})$. Treatment $\mathrm{A}$ (reference) and $\mathrm{B}$ (test) were considered to be bioequivalent if the $90 \%$ CIs for the ratio of geometric means for all primary parameters $\left(\mathrm{AUC}_{\infty}, \mathrm{AUC}_{\text {last }}\right.$, and $\left.\mathrm{C}_{\max }\right)$ fell entirely within $80 \%$ to $125 \%$.

In all studies, TEAEs were summarized by treatment within each body system and for each preferred term. Results of clinical laboratory tests, vital signs, and ECG parameters were summarized using descriptive statistics.

\section{Results}

\section{Study disposition and demographics}

The demographic and baseline characteristics were generally similar for all enrolled participants across the six studies (Table 1). The mean age of participants ranged from 32.9 to 37.8 years and the majority were white $(80 \%$ to $97 \%)$ and male ( $47 \%$ to $66 \%)$. Mean baseline body weight ranged from 72.6 to $75.4 \mathrm{~kg}$, and BMI from 25.2 to $26.1 \mathrm{~kg} / \mathrm{m}^{2}$.

The study completion and early withdrawal information across the six studies are summarized in Table 2 . Study withdrawal due to TEAEs 
Citation: Devineni D, Curtin CR, Ariyawansa J, Weiner S, Stieltjes H, et al. (2014) Bioequivalence of Canagliflozin/Metformin Immediate Release Fixed-Dose Combination Tablets Compared with Concomitant Administration of Single Components of Canagliflozin and Metformin in Healthy Fed Participants. J Bioequiv Availab 6: 164-173. doi:10.4172/jbb.1000199

\begin{tabular}{|c|c|c|c|c|c|c|}
\hline & Study 1 & Study 2 & Study 3 & Study 4 & Study 5 & Study 6 \\
\hline Characteristic & $(\mathrm{N}=64)$ & $(\mathrm{N}=74)$ & $(\mathrm{N}=64)$ & $(\mathrm{N}=64)$ & $(\mathrm{N}=64)$ & $(\mathrm{N}=83)$ \\
\hline \multicolumn{7}{|l|}{ Age (years) } \\
\hline Mean (SD) & $34.7(11.8)$ & $32.9(10.9)$ & $36.6(8.4)$ & $36.0(10.4)$ & $37.8(8.1)$ & $34.2(11.4)$ \\
\hline Range & $(19 ; 54)$ & $(19 ; 55)$ & $(19 ; 54)$ & $(18 ; 54)$ & $(21 ; 55)$ & $(20 ; 55)$ \\
\hline \multicolumn{7}{|l|}{ Sex, n (\%) } \\
\hline Female & $27(42)$ & $31(42)$ & $22(34)$ & $27(42)$ & $28(44)$ & $44(53)$ \\
\hline Male & $37(58)$ & $43(58)$ & $42(66)$ & $37(58)$ & $36(56)$ & $39(47)$ \\
\hline \multicolumn{7}{|l|}{ Race, $n(\%)$} \\
\hline White & $59(92)$ & $59(80)$ & $61(95)$ & $61(95)$ & $62(97)$ & $70(84)$ \\
\hline Black or African American & $4(6)$ & $10(14)$ & $3(5)$ & $2(3)$ & $1(2)$ & $11(13)$ \\
\hline Other & $1(2)$ & $5(7)$ & 0 & $1(2)$ & $1(2)$ & $2(2)$ \\
\hline \multicolumn{7}{|l|}{ Weight (kg) } \\
\hline Mean (SD) & $75.3(12.7)$ & $75.2(11.6)$ & $73.1(11.2)$ & $72.7(11.5)$ & $72.6(11.2)$ & 75.4 (11.7) \\
\hline Range & $(54 ; 106)$ & $(54 ; 103)$ & $(52 ; 106)$ & $(50 ; 95)$ & $(52 ; 97)$ & $(54 ; 104)$ \\
\hline \multicolumn{7}{|l|}{ Height $(\mathrm{cm})$} \\
\hline Mean (SD) & $172.4(9.6)$ & $172.1(9.8)$ & $167.9(10.1)$ & $167.4(9.8)$ & $166.4(8.7)$ & $171.5(9.0)$ \\
\hline Range & $(153 ; 190)$ & $(152 ; 196)$ & $(149 ; 192)$ & $(151 ; 191)$ & $(151 ; 184)$ & $(148 ; 191)$ \\
\hline \multicolumn{7}{|l|}{ BMI $\left(\mathbf{k g} / \mathbf{m}^{2}\right)$} \\
\hline Mean (SD) & $25.2(2.5)$ & $25.3(2.7)$ & $25.9(2.7)$ & $25.8(2.4)$ & $26.1(2.8)$ & $25.5(2.5)$ \\
\hline Range & $(21 ; 30)$ & $(19 ; 30)$ & $(20 ; 30)$ & $(21 ; 30)$ & $(20 ; 30)$ & $(20 ; 30)$ \\
\hline
\end{tabular}

Note: In each study, participants received 2 canagliflozin/metformin IR FDC tablets or equivalent doses of canagliflozin and metformin as individual component IR tablets. $\mathrm{BMI}=$ body mass index; $\mathrm{N}=$ total sample size; $\mathrm{n}=$ size of subsample; $\mathrm{SD}=$ standard deviation; $\mathrm{IR}=$ immediate release; FDC = fixed-dose combination.

Table 2: Study completion/early withdrawal information and summary of most commonly reported treatment-emergent adverse events.

\begin{tabular}{|c|c|c|c|c|c|c|}
\hline & Study 1 & Study 2 & Study 3 & Study 4 & Study 5 & Study 6 \\
\hline & $(N=64)$ & $(N=74)$ & $(N=64)$ & $(N=64)$ & $(N=64)$ & $(\mathrm{N}=83)$ \\
\hline \multicolumn{7}{|l|}{ Completion/withdrawal } \\
\hline Enrolled, $\mathbf{n}(\%)$ & $64(100)$ & $74(100)$ & $64(100)$ & $64(100)$ & $64(100)$ & $83(100)$ \\
\hline Completed, n (\%) & $59(92.2)$ & $62(83.8)$ & $58(90.6)$ & $60(93.8)$ & $61(95.3)$ & $62(74.7)$ \\
\hline Withdrawn, n (\%) & $5(7.8)$ & $12(16.2)$ & $6(9.4)$ & $4(6.3)$ & $3(4.7)$ & $21(25.3)$ \\
\hline Adverse event & $1(1.6)$ & $4(5.4)$ & $6(9.4)$ & $1(1.6)$ & $2(3.1)$ & $9(10.8)$ \\
\hline Withdrawal of consent & - & - & - & $1(1.6)$ & - & $3(3.6)$ \\
\hline Other & $4(6.3)$ & $8(10.8)$ & - & $3(4.7)$ & $1(1.6)$ & $9(10.8)$ \\
\hline \multicolumn{7}{|l|}{ Most common TEAEs } \\
\hline Any adverse event, $n(\%)$ & $35(54.7)$ & $48(64.9)$ & $35(54.7)$ & $33(51.6)$ & $44(68.8)$ & $60(72.3)$ \\
\hline Gastrointestinal disorders, n (\%) & $26(40.6)$ & $41(55.4)$ & $27(42.2)$ & $19(29.7)$ & $35(54.7)$ & $53(63.9)$ \\
\hline Diarrhea & $16(25.0)$ & $28(37.8)$ & $22(34.4)$ & $13(20.3)$ & $28(43.8)$ & $29(34.9)$ \\
\hline Nausea & $11(17.2)$ & $21(28.4)$ & $14(21.9)$ & $7(10.9)$ & $13(20.3)$ & $27(32.5)$ \\
\hline Nervous system disorders, $\mathbf{n}(\%)$ & $16(25.0)$ & $16(21.6)$ & $9(14.1)$ & $15(23.4)$ & $19(29.7)$ & $23(27.7)$ \\
\hline Headache & $13(20.3)$ & $14(18.9)$ & $7(10.9)$ & $8(12.5)$ & $15(23.4)$ & $14(16.9)$ \\
\hline
\end{tabular}

Note: Total treatment dose of canagliflozin and metformin administered as 2 IR FDC tablets or coadministered as single-component canagliflozin and metformin: 100 mg CANA, 1000 mg MET (Study 1); 100 mg CANA, 1700 mg MET (Study 2); 100 mg CANA, 2000 mg MET (Study 3); 300 mg CANA, 1000 mg MET (Study 4); 300 mg CANA $1700 \mathrm{mg}$ MET (Study 5); $300 \mathrm{mg}$ CANA, $2000 \mathrm{mg} \mathrm{MET}$ (Study 6); IR = immediate release; FDC = fixed-dose combination; CANA = canagliflozin; MET = metformin; TEAE $=$ treatment-emergent adverse events; $N=$ total sample size; $n=$ size of subsample.

was relatively infrequent and attributed primarily to vomiting within 8 hours after dosing (a study protocol withdrawal criterion). Withdrawal of consent occurred very infrequently and withdrawal due to other reasons was often attributed to non-compliance and the participant unable to complete the standard high-fat breakfast.

\section{Pharmacokinetic analyses}

Canagliflozin: Across the six studies, the canagliflozin pharmacokinetic parameters were generally similar when administered with metformin (Treatment A; reference) or as a FDC formulation (Treatment B, test) (Table 3). The mean plasma canagliflozin concentrations were similar following administration of both treatments across the range of doses (Figures 1 and 2). Median $t_{\max }$ and mean $t_{1 / 2}$ values for canagliflozin were similar for both treatments (Table 3).
For all six studies, the FDC formulation met the predefined bioequivalence criteria with respect to $\mathrm{AUC}_{\infty}, \mathrm{AUC}_{\text {last }}$, and $\mathrm{C}_{\max }$ of canagliflozin as the $90 \% \mathrm{CI}$ for the test-to-reference geometric mean ratio (GMR) of these parameters were entirely contained within the prespecified bioequivalence limits of $80 \%$ to $125 \%$, indicating that bioequivalence criteria for canagliflozin were met in each of the studies (Table 3).

Metformin: Across the six studies, the mean plasma metformin concentration-time profiles were similar after administration of the FDC formulation and the co-administered treatments (Figures 3 and 4). The median $\mathrm{t}_{\text {max }}$ and mean $\mathrm{t}_{1 / 2}$ values for metformin after administration were generally similar for both treatments (Table 4 ).

For all six studies the FDC formulation met the predefined bioequivalence criteria with respect to $A U C_{\infty}, A C_{\text {last }}$, and $C_{\max }$ of 
Citation: Devineni D, Curtin CR, Ariyawansa J, Weiner S, Stieltjes H, et al. (2014) Bioequivalence of Canagliflozin/Metformin Immediate Release Fixed-Dose Combination Tablets Compared with Concomitant Administration of Single Components of Canagliflozin and Metformin in Healthy Fed Participants. J Bioequiv Availab 6: 164-173. doi:10.4172/jbb.1000199

Table 3: Summary statistics for geometric means and ratio of geometric means with corresponding $90 \%$ confidence intervals for canagliflozin pharmacokinetic parameters following administration of 2 IR FDC tablets $(50$ or $100 \mathrm{mg}$ canagliflozin/500, 850 , or $1,000 \mathrm{mg}$ metformin) compared to coadministration of individual IR canagliflozin (100 or $300 \mathrm{mg}$ ) and 2 metformin $(500,850$, and 1,000 $\mathrm{mg}$ ) tablets at equivalent doses.

\begin{tabular}{|c|c|c|c|}
\hline & $\begin{array}{l}\text { Treatment A } \\
\text { (Reference) }\end{array}$ & Treatment B (Test) & Test/Reference \\
\hline \multicolumn{4}{|l|}{ STUDY 1} \\
\hline Parameter & $\begin{array}{l}100 \mathrm{mg} \text { CANA + } 2 \\
\times 500 \mathrm{mg} \mathrm{MET} \text { IR } \\
(\mathrm{n}=58)\end{array}$ & $\begin{array}{l}2 \times(50 \mathrm{mg} \\
\text { CANA/500 mg } \\
\text { MET) IR FDC } \\
(\mathrm{n}=58)\end{array}$ & $\begin{array}{l}\text { Estimated Ratio, \% } \\
(90 \% \mathrm{Cl}) \\
\text { (Test/Ref.) }\end{array}$ \\
\hline $\mathrm{C}_{\max }(\mathrm{ng} / \mathrm{mL})$ & 722.50 & 679.01 & $93.98(86.10-102.58)$ \\
\hline $\mathrm{AUC}_{\text {last }}$ & 8523.60 & 8561.16 & $100.44(98.27-102.66)$ \\
\hline $\begin{array}{l}\operatorname{AUC}_{\infty}(n g \cdot h / \\
m L)^{a}\end{array}$ & 8815.54 & 8808.21 & $99.92(97.68-102.20)$ \\
\hline$t_{\max }(h)$ & $3.00(0.98-12.00)^{b}$ & $3.00(1.00-16.00)^{c}$ & \\
\hline$t_{1 / 2}(h)$ & $13.7(2.75)^{\mathrm{d}}$ & $13.7(2.84)^{\mathrm{e}}$ & \\
\hline \multicolumn{4}{|l|}{ STUDY 2} \\
\hline Parameter & $\begin{array}{l}100 \mathrm{mg} \text { CANA + } 2 \\
\text { X } 850 \mathrm{mg} \text { MET IR } \\
(\mathrm{n}=62)\end{array}$ & $\begin{array}{l}2 \times(50 \mathrm{mg} \\
\text { CANA/850 mg } \\
\text { MET) IR FDC } \\
(\mathrm{n}=62)\end{array}$ & $\begin{array}{l}\text { Estimated Ratio, \% } \\
(90 \% \mathrm{Cl}) \\
\text { (Test/Ref.) }\end{array}$ \\
\hline $\mathrm{C}_{\text {max }}(\mathrm{ng} / \mathrm{mL})$ & 705.28 & 740.96 & $105.06(97.89-112.76)$ \\
\hline $\mathrm{AUC}_{\text {last }}$ & 8370.97 & 8487.99 & $101.40(99.73-103.10)$ \\
\hline $\begin{array}{l}\mathrm{AUC}_{\infty}(\mathrm{ng} \cdot \mathrm{h} / \\
\mathrm{mL})\end{array}$ & 8632.52 & 8748.88 & $101.35(99.62-103.10)$ \\
\hline$t_{\max }(h)$ & $3.52(1.00-10.00)^{f}$ & $3.00(1.00-10.00)^{9}$ & \\
\hline$t_{1 / 2}(h)$ & $14.4(3.14)^{f}$ & $14.5(2.89)^{9}$ & \\
\hline \multicolumn{4}{|l|}{ STUDY 3} \\
\hline Parameter & $\begin{array}{l}100 \mathrm{mg} \text { CANA + } 2 \\
\text { X } 1000 \mathrm{mg} \text { MET IR } \\
(\mathrm{n}=57)\end{array}$ & $\begin{array}{l}2 \times(50 \mathrm{mg} \\
\text { CANA/1000 mg } \\
\text { MET) IR FDC } \\
(n=57)\end{array}$ & $\begin{array}{l}\text { Estimated Ratio, \% } \\
(90 \% \mathrm{Cl}) \\
\text { (Test/Ref.) }\end{array}$ \\
\hline $\mathrm{C}_{\max }(\mathrm{ng} / \mathrm{mL})$ & 803.00 & 775.90 & $96.62(89.12-104.77)$ \\
\hline $\mathrm{AUC}_{\text {last }}$ & 8609.25 & 8752.70 & 101.67 (99.33-104.06) \\
\hline $\begin{array}{l}\mathrm{AUC}_{\infty}(\mathrm{ng} \cdot \mathrm{h} / \\
\mathrm{mL})^{\mathrm{a}}\end{array}$ & 8904.71 & 9078.94 & $101.96(99.57-104.40)$ \\
\hline$t_{\max }(h)$ & $4.00(1.00-10.00)$ & $3.00(1.00-10.00)^{\mathrm{h}}$ & \\
\hline$t_{1 / 2}(h)$ & $13.92(2.96)^{i}$ & $14.47(3.45)^{c}$ & \\
\hline \multicolumn{4}{|l|}{ STUDY 4} \\
\hline Parameter & $\begin{array}{l}300 \mathrm{mg} \text { CANA + } 2 \\
\text { X } 500 \mathrm{mg} \text { MET IR } \\
(\mathrm{n}=60)\end{array}$ & $\begin{array}{l}2 \times(150 \mathrm{mg} \\
\text { CANA/500 mg } \\
\text { MET) IR FDC } \\
(\mathrm{n}=60)\end{array}$ & $\begin{array}{l}\text { Estimated Ratio, \% } \\
(90 \% \mathrm{Cl})\end{array}$ \\
\hline $\mathrm{C}_{\max }(\mathrm{ng} / \mathrm{mL})$ & 2558.49 & 2673.78 & $104.51(98.47-110.92)$ \\
\hline $\mathrm{AUC}_{\text {last }}$ & 27679.43 & 28125.42 & 101.61 (99.94-103.31) \\
\hline $\begin{array}{l}\mathrm{AUC}_{\infty}(\mathrm{ng} \cdot \mathrm{h} / \\
\mathrm{mL})^{\mathrm{c}}\end{array}$ & 28262.76 & 28707.97 & $101.58(99.84-103.34)$ \\
\hline$t_{\max }(h)$ & $4.00(1.00-12.00)^{j}$ & $3.00(1.50-10.03)^{b}$ & \\
\hline$t_{1 / 2}(h)$ & $13.9(2.49)^{j}$ & $14.1(2.79)^{d}$ & \\
\hline \multicolumn{4}{|l|}{ STUDY 5} \\
\hline Parameter & $\begin{array}{l}300 \mathrm{mg} \text { CANA + } 2 \\
\text { X } 850 \mathrm{mg} \mathrm{MET} \text { IR } \\
(\mathrm{n}=61)\end{array}$ & $\begin{array}{l}2 \times(150 \mathrm{mg} \\
\text { CANA/850 mg } \\
\text { MET) IR FDC } \\
(\mathrm{n}=61)\end{array}$ & $\begin{array}{l}\text { Estimated Ratio, \% } \\
(90 \% \mathrm{Cl}) \\
\text { (Test/Ref.) }\end{array}$ \\
\hline $\mathrm{C}_{\max }(\mathrm{ng} / \mathrm{mL})$ & 2527.63 & 2606.24 & $103.11(95.91-110.86)$ \\
\hline$A \cup C_{\text {last }}$ & 30037.82 & 30344.32 & $101.02(99.60-102.47)$ \\
\hline $\begin{array}{l}\mathrm{AUC}_{\mathrm{o}}(\mathrm{ng} \cdot \mathrm{h} / \\
\mathrm{mL})^{\mathrm{h}}\end{array}$ & 30852.23 & 31148.41 & $100.96(99.44-102.50)$ \\
\hline$t_{\max }(h)$ & $3.00(1.50-12.02)^{b}$ & $3.00(1.00-12.00)^{d}$ & \\
\hline$t_{1 / 2}(h)$ & $14.80(3.08)^{\mathrm{d}}$ & $14.89(3.45)^{d}$ & \\
\hline \multicolumn{4}{|l|}{ STUDY 6} \\
\hline
\end{tabular}

\begin{tabular}{|l|l|l|l|}
\hline Parameter & $\begin{array}{l}300 \mathrm{mg} \text { CANA + 2 } \\
\text { X 1000 mg MET IR } \\
(\mathrm{n}=62)\end{array}$ & $\begin{array}{l}2 \times(150 \mathrm{mg} \\
\text { CANA/1000 mg } \\
\text { MET) IR FDC } \\
(\mathrm{n}=62)\end{array}$ & $\begin{array}{l}\text { Estimated Ratio, \% } \\
(90 \% \text { Cl) } \\
(\text { Test/Ref. })\end{array}$ \\
\hline $\mathrm{C}_{\text {max }}(\mathrm{ng} / \mathrm{mL})$ & 2099.09 & 2225.02 & $106.00(97.90-114.77)$ \\
\hline AUC $_{\text {last }}$ & 26960.48 & 27560.10 & $102.22(100.00-104.50)$ \\
\hline $\begin{array}{l}\mathrm{AUC}_{\infty}(\mathrm{ng} \cdot \mathrm{h} / \\
\mathrm{mL})^{\mathrm{j}}\end{array}$ & 27561.67 & 28234.55 & $102.44(100.21-104.72)$ \\
\hline $\mathrm{t}_{\max }(\mathrm{h})$ & $4.00(0.98-24.00)^{\mathrm{g}}$ & $3.00(0.98-16.00)^{\mathrm{g}}$ & \\
\hline $\mathrm{t}_{1 / 2}(\mathrm{~h})$ & $14.29(2.68)^{\mathrm{k}}$ & $14.47(2.88)^{\mathrm{k}}$ & \\
\hline
\end{tabular}

Note: metformin IR tablets supplied as Glucophage ${ }^{\circledR}$ IR tablets. ${ }^{a} n=55 ;{ }^{b} n=63$;

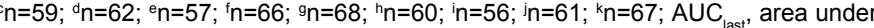
the plasma concentration-time curve from time 0 to the time of the last quantifiable concentration; $\mathrm{AUC}_{\infty}$, area under the plasma concentration-time curve from time 0 to infinite time; $\mathrm{Cl}$ : confidence interval; $\mathrm{C}_{\max }$, maximum observed plasma concentration; $\mathrm{n}$ : total number of participants; Ref=reference; $t_{1 / 2}(h)$, terminal elimination half-time and represented by arithmetic mean (SD); $t_{\text {max }}(h)$, time to reach the maximum plasma concentration and reported as median (range).

metformin as the $90 \%$ CI for the test-to-reference GMRs of these parameters were entirely contained within the prespecified bioequivalence limits of $80 \%$ to $125 \%$, indicating bioequivalence criteria for metformin were met in each of the studies (Table 4).

Safety and tolerability: Across the six studies, single doses of canagliflozin and metformin administered as either the FDC treatment or the co-administered treatment were generally well-tolerated, other than gastrointestinal adverse events known to be associated with metformin (Table 2). Almost all gastrointestinal TEAEs were assessed by the investigator as possibly, probably or very likely related to metformin. The incidence, type, and duration of specific TEAEs were generally similar between the two treatment formulations. The majority of the reported TEAEs were mild, transient and resolved by the end of the study, with only one serious TEAE (radiculopathy due to a herniated disc) which was assessed by the investigator as not related to study drug (FDC $300 \mathrm{mg} / 2,000 \mathrm{mg}$ group). No hypoglycemic events were reported in any of the studies. No deaths were reported.

Overall, the incidence of TEAEs in the studies varied from $51.6 \%$ in Study 4 to $72.3 \%$ in Study 6. The most commonly reported TEAEs by system organ class (SOC) were gastrointestinal system disorders (incidence ranged from $29.7 \%$ in Study 4 to $63.9 \%$ in Study 6 ) and nervous system disorders (incidence ranged from 14.1\% in Study 3 to $29.7 \%$ in Study 5). The incidence of diarrhea and nausea in the studies where canagliflozin $300 \mathrm{mg}$ dose was administered tended to increase with greater metformin dose. The most commonly reported TEAEs were diarrhea, nausea, and headache. Overall, the incidence of TEAEs in Treatment A was similar to Treatment B.

For all studies, there were no treatment-related mean changes from baseline (day-1) in any of the routine clinical laboratory safety tests (i.e., hematology, chemistry, and urinalysis) that were considered to be clinically significant. There were no consistent treatment-related changes from baseline in mean vital sign measurements (i.e., pulse rate or blood pressure), ECG parameters, or physical examinations.

\section{Discussion}

Long-term Phase 3 clinical studies of canagliflozin in patients with T2DM inadequately controlled with metformin, or dual therapy with metformin plus sulphonylurea or metformin plus pioglitazone, have established efficacy of canagliflozin in achieving improvements in fasting plasma glucose and $\mathrm{HbA}_{1 c}$ reduction with additional weight loss and reduction in blood pressure,with a favorable safety and tolerability profile. In these Phase 3 studies, patients received canagliflozin 100 
Citation: Devineni D, Curtin CR, Ariyawansa J, Weiner S, Stieltjes H, et al. (2014) Bioequivalence of Canagliflozin/Metformin Immediate Release Fixed-Dose Combination Tablets Compared with Concomitant Administration of Single Components of Canagliflozin and Metformin in Healthy Fed Participants. J Bioequiv Availab 6: 164-173. doi:10.4172/jbb.1000199
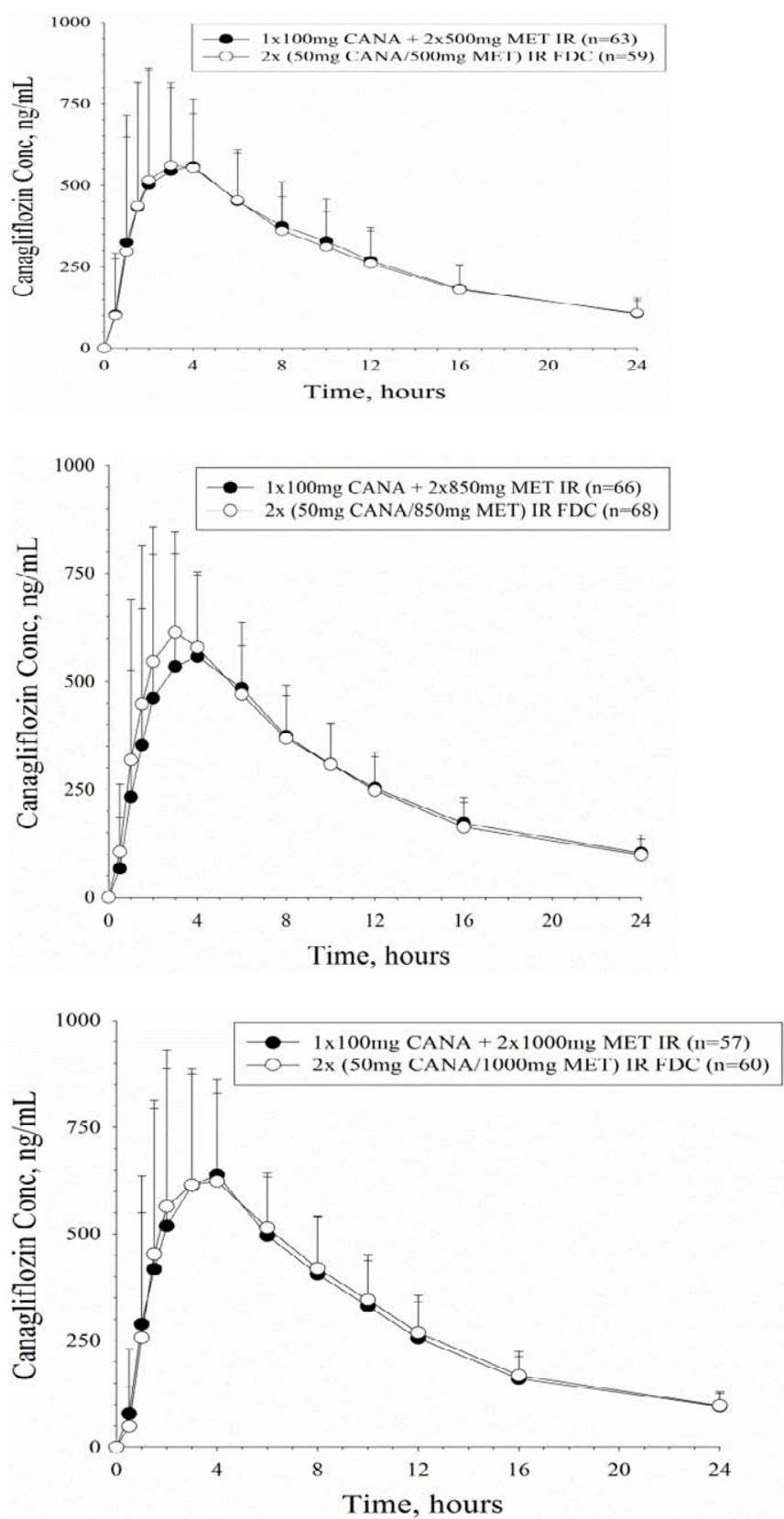

Figure 1: Mean (SD) plasma concentration-time profiles for canagliflozin following administration of two canagliflozin/metformin FDC IR tablets (A) 50 $\mathrm{mg} / 500 \mathrm{mg}$ (B) $50 \mathrm{mg} / 850 \mathrm{mg}$ and (C) $50 \mathrm{mg} / 1,000 \mathrm{mg}$ and coadministration of canagliflozin + metformin IR individual tablets (A) $100 \mathrm{mg}+2 \times 500 \mathrm{mg}(\mathrm{B})$ $100 \mathrm{mg}+2 \times 850 \mathrm{mg}$ and (C) $100 \mathrm{mg}+2 \times 1,000 \mathrm{mg}$ (Studies 1-3).

and $300 \mathrm{mg}$ QD and were on stable metformin therapy at $\geq 2,000 \mathrm{mg} /$ day or $\geq 1,500 \mathrm{mg} /$ day if unable to tolerate a higher dose $[26,33,34]$. In a drug-drug interaction study, healthy participants received single daily oral doses of canagliflozin $300 \mathrm{mg}$ and metformin $2,000 \mathrm{mg}$, and no clinically meaningful interaction between the pharmacokinetics of either drug was observed suggesting that the two drugs could be combined into a single FDC tablet [35].

The present studies evaluated the bioequivalence of an IR FDC tablet of canagliflozin and metformin as compared to co-administration of individual single-component IR tablets at corresponding doses in healthy fed participants. The bioequivalence studies used six dose strengths of the IR FDC tablets formulated to contain 50 or $150 \mathrm{mg}$ canagliflozin combined with metformin at 500,850 or $1,000 \mathrm{mg}$.
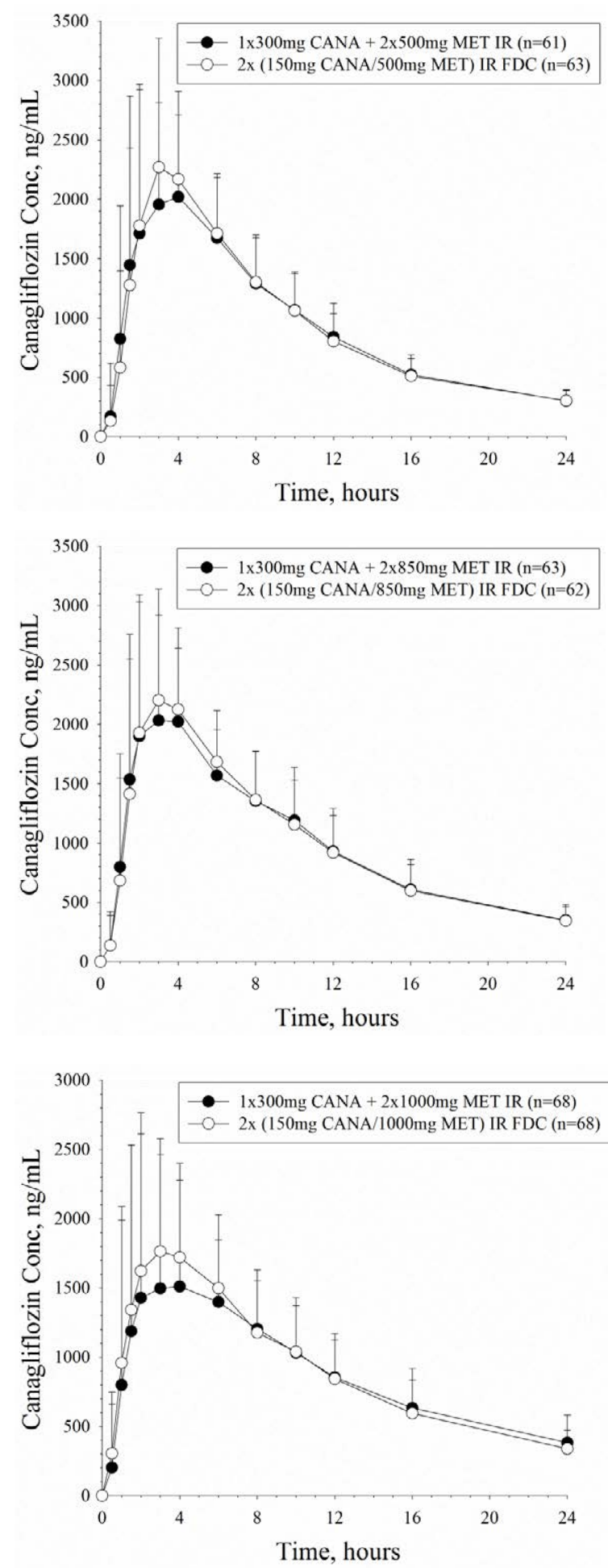

Figure 2: Mean (SD) plasma concentration-time profiles for canagliflozin following administration of two canagliflozin/metformin FDC IR tablets (A) 150 $\mathrm{mg} / 500 \mathrm{mg} \mathrm{(B)} 150 \mathrm{mg} / 850 \mathrm{mg}$ and (C) $150 \mathrm{mg} / 1,000 \mathrm{mg}$ and coadministration of canagliflozin + metformin IR individual tablets (A) $300 \mathrm{mg}+2 \times 500 \mathrm{mg}(\mathrm{B})$ $300 \mathrm{mg}+2 \times 850 \mathrm{mg}$, and (C) $300 \mathrm{mg}+2 \times 1,000 \mathrm{mg}$ (Studies 4-6). 
Citation: Devineni D, Curtin CR, Ariyawansa J, Weiner S, Stieltjes H, et al. (2014) Bioequivalence of Canagliflozin/Metformin Immediate Release Fixed-Dose Combination Tablets Compared with Concomitant Administration of Single Components of Canagliflozin and Metformin in Healthy Fed Participants. J Bioequiv Availab 6: 164-173. doi:10.4172/jbb.1000199
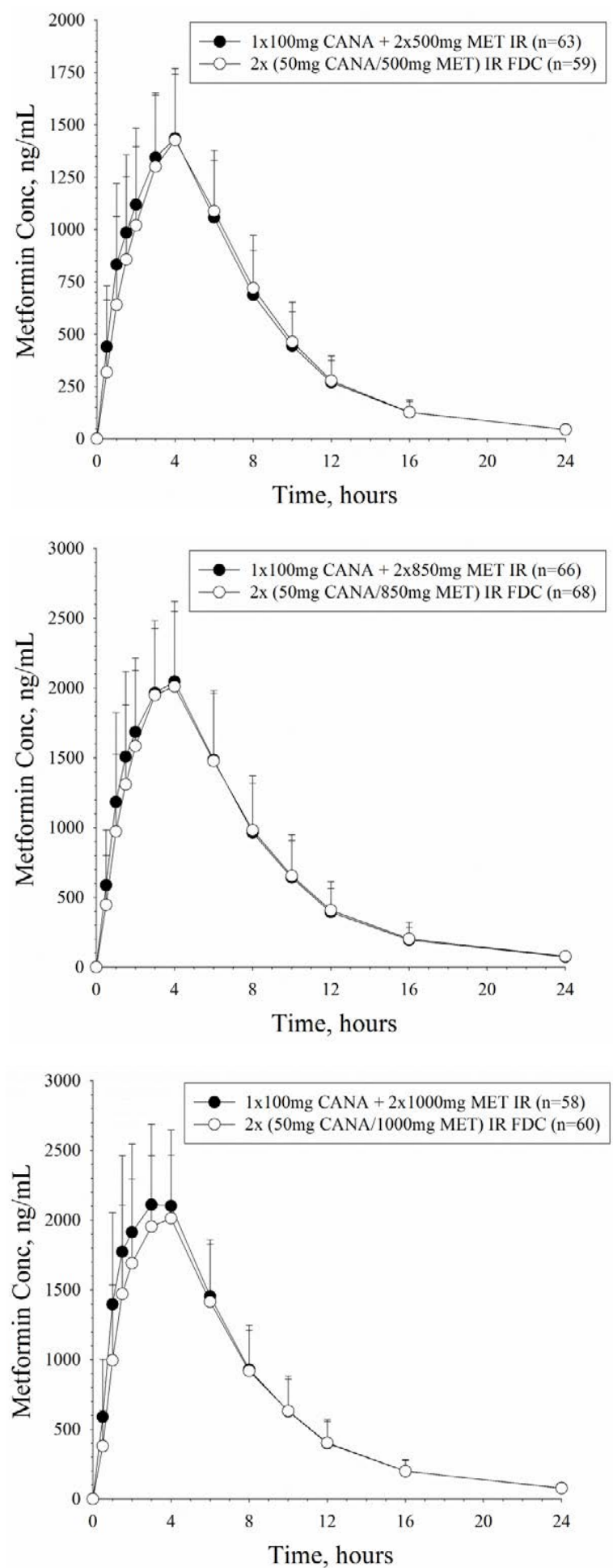

Figure 3: Mean (SD) plasma concentration-time profiles for metformin following administration of two canagliflozin/metformin FDC IR tablets (A) 50 $\mathrm{mg} / 500 \mathrm{mg}(\mathrm{B}) 50 \mathrm{mg} / 850 \mathrm{mg}$ and $(\mathrm{C}) 50 \mathrm{mg} / 1000 \mathrm{mg}$ and coadministration of canagliflozin + metformin IR individual tablets (A) $100 \mathrm{mg}+2 \times 500 \mathrm{mg}$, (B) 100 $\mathrm{mg}+2 \times 850 \mathrm{mg}$, and $(\mathrm{C}) 100 \mathrm{mg}+2 \times 1,000 \mathrm{mg}$ (Studies $1-3)$

These studies involved oral administration of single doses of 100 or $300 \mathrm{mg}$ of canagliflozin and $1,000,1,700$ or $2,000 \mathrm{mg}$ metformin $\mathrm{HCl}$ (Glucophage $^{\mathbb{R}}$ ) either as canagliflozin/metformin IR FDC tablets or as tablets of the individual components. As the to-be-marketed singleagent canagliflozin tablets used as reference treatment are only available in tablet strengths of 100 or $300 \mathrm{mg}$, two canagliflozin/metformin IR
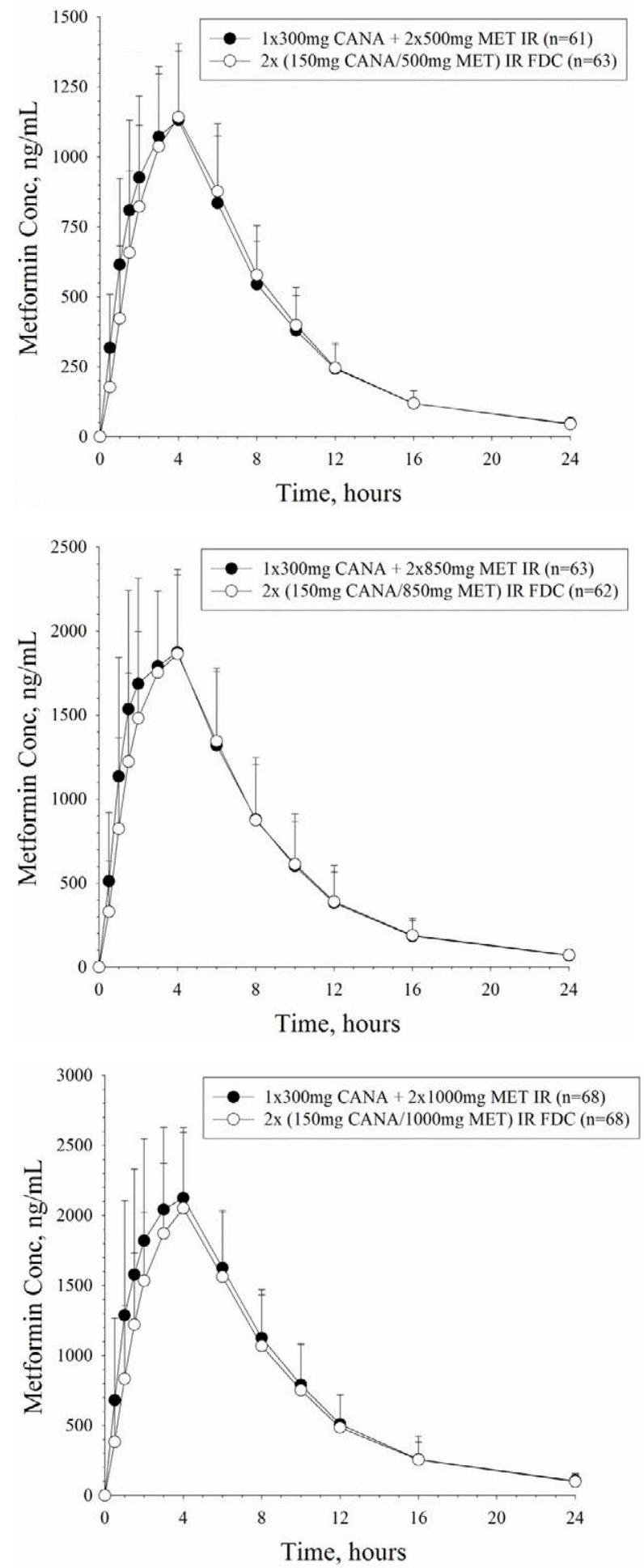

Figure 4: Mean (SD) plasma concentration-time profiles for metformin following administration of two canagliflozin/metformin FDC IR tablets (A) 150 $\mathrm{mg} / 500 \mathrm{mg} \mathrm{(B)} 150 \mathrm{mg} / 850 \mathrm{mg}$ and (C) $150 \mathrm{mg} / 1000 \mathrm{mg}$ and coadministration of canagliflozin + metformin IR individual tablets (A) $300 \mathrm{mg}+2 \times 500 \mathrm{mg}$ (B) $300 \mathrm{mg}+2 \times 850 \mathrm{mg}$ and (C) $300 \mathrm{mg}+2 \times 1,000 \mathrm{mg}$ (Studies 4-6). 
Citation: Devineni D, Curtin CR, Ariyawansa J, Weiner S, Stieltjes H, et al. (2014) Bioequivalence of Canagliflozin/Metformin Immediate Release Fixed-Dose Combination Tablets Compared with Concomitant Administration of Single Components of Canagliflozin and Metformin in Healthy Fed Participants. J Bioequiv Availab 6: 164-173. doi:10.4172/jbb.1000199

Table 4: Summary statistics for geometric means and ratio of geometric means with corresponding $90 \%$ confidence intervals for metformin pharmacokinetic parameters following administration of 2 IR FDC tablets (50 or $100 \mathrm{mg}$ canagliflozin/500, 850, or $1,000 \mathrm{mg}$ metformin) compared to coadministration of individual IR canagliflozin (100 or $300 \mathrm{mg}$ ) and 2 metformin $(500,850$, and $1,000 \mathrm{mg})$ tablets at equivalent doses.

\begin{tabular}{|c|c|c|c|}
\hline & Treatment A (Reference) & Treatment B (Test) & Test/Ref \\
\hline \multicolumn{4}{|c|}{ STUDY 1} \\
\hline Parameter & 100 mg CANA + 2 X 500 mg MET IR $(n=58)$ & $2 \times(50 \mathrm{mg}$ CANA/500 mg MET) IR FDC $(n=58)$ & Estimated Ratio, \% (90\% Cl) (Test/Ref.) \\
\hline $\mathrm{C}_{\max }(\mathrm{ng} / \mathrm{mL})$ & 1507.20 & 1471.39 & $97.62(94.32-101.05)$ \\
\hline $\mathrm{AUC}_{\text {last }}$ & 11436.06 & 11300.29 & $98.81(96.07-101.63)$ \\
\hline $\mathrm{AUC}_{\infty}(\mathrm{ng} \cdot \mathrm{h} / \mathrm{mL})^{\mathrm{a}}$ & 11804.70 & 11648.74 & $98.68(95.80-101.64)$ \\
\hline $\mathrm{t}_{\max }(\mathrm{h})$ & $4.00(0.98-6.00)^{\mathrm{b}}$ & $4.00(1.00-8.00)^{c}$ & \\
\hline$t_{1 / 2}(h)$ & $4.28(0.966)^{\mathrm{b}}$ & $4.13(0.719)$ & \\
\hline \multicolumn{4}{|c|}{ STUDY 2} \\
\hline Parameter & 100 mg CANA + 2 X 850 mg MET IR $(n=62)$ & $2 \times(50 \mathrm{mg}$ CANA/850 mg MET) IR FDC $(n=62)$ & Estimated Ratio, \% (90\% Cl) (Test/Ref.) \\
\hline $\mathrm{C}_{\max }(\mathrm{ng} / \mathrm{mL})$ & 2181.83 & 2145.93 & $98.35(95.31-101.49)$ \\
\hline $\mathrm{AUC}_{\text {last }}$ & 16322.17 & 16098.88 & $98.63(95.85-101.50)$ \\
\hline $\mathrm{AUC}_{\infty}(\mathrm{ng} \cdot \mathrm{h} / \mathrm{mL})$ & 16775.23 & 16602.04 & $98.97(96.18-101.84)$ \\
\hline $\mathrm{t}_{\max }(\mathrm{h})$ & $4.00(1.00-6.23)^{d}$ & $4.00(1.50-6.00)^{\mathrm{e}}$ & \\
\hline $\mathrm{t}_{1 / 2}(\mathrm{~h})$ & $4.54(0.67)^{d}$ & $4.65(1.13)^{\mathrm{e}}$ & \\
\hline \multicolumn{4}{|c|}{ STUDY 3} \\
\hline Parameter & 100 mg CANA + $2 \times 1000$ mg MET IR $(n=58)$ & $2 \times(50 \mathrm{mg}$ CANA/1000 mg MET) IR FDC $(n=58)$ & Estimated Ratio, \% (90\% Cl) (Test/Ref.) \\
\hline $\mathrm{C}_{\max }(\mathrm{ng} / \mathrm{mL})$ & 2274.31 & 2141.21 & $94.15(91.00-97.40)$ \\
\hline $\mathrm{AUC}_{\text {last }}$ & 16828.48 & 15899.55 & $94.48(91.90-97.13)$ \\
\hline $\mathrm{AUC}_{\infty}(\mathrm{ng} \cdot \mathrm{h} / \mathrm{mL})^{f}$ & 17327.58 & 16447.21 & $94.92(92.14-97.78)$ \\
\hline$t_{\max }(h)$ & $3.00(1.00-6.00)$ & $3.98(1.50-6.00)^{9}$ & \\
\hline $\mathrm{t}_{1 / 2}(\mathrm{~h})$ & $4.68(1.09)^{f}$ & $4.79(1.09)^{9}$ & \\
\hline \multicolumn{4}{|c|}{ STUDY 4} \\
\hline Parameter & 300 mg CANA + 2 X 500 mg MET IR $(n=60)$ & $2 \times(150 \mathrm{mg}$ CANA/500 mg MET) IR FDC $(n=60)$ & Estimated Ratio, \% (90\% Cl) (Test/Ref.) \\
\hline $\mathrm{C}_{\max }(\mathrm{ng} / \mathrm{mL})$ & 1195.92 & 1178.57 & $98.55(94.91-102.33)$ \\
\hline $\mathrm{AUC}_{\text {last }}$ & 9292.72 & 9256.26 & $99.61(96.17-103.17)$ \\
\hline $\mathrm{AUC}_{\infty}(\mathrm{ng} \cdot \mathrm{h} / \mathrm{mL})$ & 9615.39 & 9543.12 & $99.25(95.74-102.89)$ \\
\hline $\mathrm{t}_{\max }(\mathrm{h})$ & $4.00(0.98-6.03)^{\mathrm{h}}$ & $4.00(1.50-7.98)^{b}$ & \\
\hline$t_{1 / 2}(h)$ & $4.64(1.17)^{\mathrm{h}}$ & $4.51(1.01)^{\mathrm{b}}$ & \\
\hline \multicolumn{4}{|c|}{ STUDY 5} \\
\hline Parameter & $300 \mathrm{mg}$ CANA + 2 X 850 mg MET IR $(n=61)$ & $2 \times(150 \mathrm{mg}$ CANA/850 mg MET) IR FDC $(n=61)$ & Estimated Ratio, \% (90\% Cl) (Test/Ref.) \\
\hline $\mathrm{C}_{\max }(\mathrm{ng} / \mathrm{mL})$ & 2042.38 & 1910.31 & $93.53(90.00-97.20)$ \\
\hline $\mathrm{AUC}_{\text {last }}$ & 15013.95 & 14537.47 & $96.83(93.92-99.83)$ \\
\hline$A \cup C_{\infty}(n g \cdot h / m L)^{c}$ & 15614.58 & 15184.15 & $97.24(94.24-100.34)$ \\
\hline$t_{\max }(h)$ & $3.00(0.98-6.00)^{b}$ & $4.00(0.98-6.00)^{i}$ & \\
\hline$t_{1 / 2}(h)$ & $4.67(1.08)^{i}$ & $4.71(0.98)$ & \\
\hline \multicolumn{4}{|c|}{ STUDY 6} \\
\hline Parameter & 300 mg CANA + 2 X 1000 mg MET IR $(n=62)$ & $2 \times(150$ mg CANA/1000 mg MET IR) FDC $(n=62)$ & Estimated Ratio, \% (90\% Cl) (Test/Ref.) \\
\hline $\mathrm{C}_{\max }(\mathrm{ng} / \mathrm{mL})$ & 2309.04 & 2099.46 & $90.92(87.03-94.99)$ \\
\hline $\mathrm{AUC}_{\text {last }}$ & 18256.73 & 16873.75 & $92.42(89.42-95.54)$ \\
\hline $\mathrm{AUC}_{\infty}(\mathrm{ng} \cdot \mathrm{h} / \mathrm{mL})^{\mathrm{j}}$ & 19026.61 & 17471.82 & $91.83(88.82-94.93)$ \\
\hline$t_{\max }(h)^{d}$ & $4.00(1.00-6.00)^{\mathrm{e}}$ & $4.00(1.00-10.00)^{\mathrm{e}}$ & \\
\hline$t_{1 / 2}(h)^{d}$ & $5.01(0.89)^{\mathrm{d}}$ & $5.06(0.90)^{d}$ & \\
\hline
\end{tabular}

Note: metformin IR tablets supplied as Glucophage ${ }^{\circledR}$ IR tablets. ${ }^{a} n=57 ;{ }^{b} n=63 ;{ }^{c} n=59 ;{ }^{d} n=66 ;{ }^{e} n=68 ;{ }^{n} n=56 ;{ }^{9} n=60 ;{ }^{n} n=61 ;{ }^{i} n=62 ;{ }^{i} n=58 ;$ AUC concentration-time curve from time 0 to the time of the last quantifiable concentration; $\mathrm{AUC}_{\infty}$, area under the plasma concentration-time curve from time 0 to infinite time; $\mathrm{Cl}$ : confidence interval; $C_{\max }$, maximum observed plasma concentration; $n$ : total number of participants; Ref: reference; $t_{1 / 2}(h)$, terminal elimination half-time and represented by arithmetic mean $(S D) ; t_{\max }(h)$, time to reach the maximum plasma concentration and reported as median (range).

FDC tablets containing 50 or $150 \mathrm{mg}$ canagliflozin were administered to provide these same daily doses.

These bioequivalence studies were conducted under fed conditions because metformin $\mathrm{HCl}$ IR is recommended to be taken with meals to reduce the incidence of gastrointestinal side effects [8,9]. In addition, no meaningful effect of food on the pharmacokinetics of canagliflozin was observed when canagliflozin tablet was administered under fed versus fasted conditions [36].
For all doses of canagliflozin and metformin, the 90\% CI for the test-to-reference GMR of AUC, $\mathrm{AUC}_{\text {last }}$, and $\mathrm{C}_{\max }$ were close to $100 \%$ and entirely contained within the prespecified bioequivalence limits of $80 \%$ to $125 \%$. This indicates that the FDC is bioequivalent to coadministration with respect to either canagliflozin or metformin pharmacokinetics with no effects on its rate and extent of absorption as well as its elimination attributed to the formulation performance factors of the FDC tablet. Canagliflozin pharmacokinetics from administration of FDC and co-administration of individual tablets 
Citation: Devineni D, Curtin CR, Ariyawansa J, Weiner S, Stieltjes H, et al. (2014) Bioequivalence of Canagliflozin/Metformin Immediate Release Fixed-Dose Combination Tablets Compared with Concomitant Administration of Single Components of Canagliflozin and Metformin in Healthy Fed Participants. J Bioequiv Availab 6: 164-173. doi:10.4172/jbb.1000199

were consistent with single- and multi-dose pharmacokinetics of canagliflozin alone $(50,100$, and $300 \mathrm{mg}$ ) in healthy participants and in adults with T2DM that showed $\mathrm{C}_{\max }$ and AUC increased in a dose-dependent manner across all 3 doses [37,38]. The single-dose pharmacokinetics of metformin observed in the bioequivalent studies are consistent with previously reported studies of metformin alone in healthy participants [39].

The evidence for the efficacy and safety of the canagliflozin/ metformin IR FDC for the target indication is primarily derived from six multinational Phase 3 studies which used locally-sourced approved metformin from each country. In the US, the patients with T2DM in Phase 3 pivotal studies received US-sourced Glucophage or the generic equivalent. In the reported bioequivalence studies, the reference tablets were canagliflozin 100 and $300 \mathrm{mg}$ and metformin was US sourced Glucophage $^{\oplus} 500,850$ and $1000 \mathrm{mg}$ tablets, thus providing support for bridging of the safety and efficacy data from prior clinical studies of canagliflozin and metformin co-administered monotherapies to the FDC tablet $[25,26,33,34]$

The safety findings observed in these studies are consistent with those previously reported for concomitant administration of canagliflozin $(300 \mathrm{mg} /$ day) with metformin $(2,000 \mathrm{mg} /$ day $)$ in healthy participants in which the incidence of the most prevalent TEAEs (gastrointestinal disorders) were more common with metformin alone as compared with canagliflozinalone [35]. Findings from 52-week canagliflozin Phase 3 clinical studies in T2DM patients demonstrated favorable safety and tolerability of canagliflozin (100 or $300 \mathrm{mg}$ ) when administered concomitantly with metformin, metformin plus sulfonylurea, or metformin plus pioglitazone [24-26,33].

\section{Conclusions}

The results of six pivotal bioequivalence studies in healthy fed participants demonstrated that the pharmacokinetics of canagliflozin and metformin across six dose levels are bioequivalent, and unaffected by formulation of the two components whether administered as an IR FDC tablet or co-administered as individual component IR tablets. Single doses of the canagliflozin/metformin IR FDC tablet or the individual tablets of canagliflozin and metformin were generally well-tolerated, other than gastrointestinal adverse events known to be associated with metformin. These results provide support for administration of the FDC tablet as an alternative option to coadministration of the individual monotherapies with the added benefits of enhanced patient compliance and convenience.

\section{Acknowledgments and Disclosures}

The studies presented in this report were funded by Janssen Research \& Development, LLC. The sponsor also provided a formal review of this manuscript. We acknowledge Dr. Bradford Challis (Janssen Research \& Development, LLC) for providing writing assistance and editorial support for the development of this manuscript. We also acknowledge Sarah Rusch (Janssen Research \& Development, a division of Janssen Pharmaceutica NV) for her statistical support The authors also thank the study participants of the six studies, without whom the studies would never have been accomplished, and the investigators for their participation in the studies: United States: Stephen Youngberg, MD; Terry O'Reilly, MD

All authors are employees of Janssen Research \& Development, LLC or of Janssen Research \& Development, a division of Janssen Pharmaceutica NV, and hold stock/stock options in the company. All authors meet ICMJE criteria and all those who fulfilled those criteria are listed as authors. All authors had access to the study data, provided direction and comments on the manuscript, made the final decision about where to publish these data, and approved submission to this journal. All authors contributed to the data interpretation, development, and review of this manuscript.

\section{References}

1. National Institute of Health and Care Excellence (2009) Type 2 diabetes: newer agents for blood glucose control in type 2 diabetes. NICE short clinical guideline 87.

2. Inzucchi SE, Bergenstal RM, Buse JB, Diamant M, Ferrannini E, et al (2012) Management of hyperglycemia in type 2 diabetes: a patient-centered approach: position statement of the American Diabetes Association (ADA) and the European Association for the Study of Diabetes (EASD). Diabetes Care 35: 1364-1379.

3. Cook MN, Girman CJ, Stein PP, Alexander CM (2007) Initial monotherapy with either metformin or sulphonylureas often fails to achieve or maintain current glycaemic goals in patients with Type 2 diabetes in UK primary care. Diabet Med 24: 350-358.

4. Nathan DM, Buse JB, Davidson MB, Heine RJ, Holman RR, et al. (2006) Management of hyperglycemia in type 2 diabetes: A consensus algorithm for the initiation and adjustment of therapy: a consensus statement from the American Diabetes Association and the European Association for the Study of Diabetes. Diabetes Care 29: 1963-1972.

5. Turner RC, Cull CA, Frighi V, Holman RR (1999) Glycemic control with diet sulfonylurea, metformin, or insulin in patients with type 2 diabetes mellitus: progressive requirement for multiple therapies (UKPDS 49). UK Prospective Diabetes Study (UKPDS) Group. JAMA 281: 2005-2012.

6. Viollet B, Guigas B, Sanz Garcia N, Leclerc J, Foretz M, et al. (2012) Cellular and molecular mechanisms of metformin: an overview. ClinSci (Lond) 122 253-270.

7. Shomali M (2011) Add-on therapies to metformin for type 2 diabetes. Expert OpinPharmacother 12: 47-62.

8. GLUCOPHAGE ${ }^{\mathrm{TM}}$ prescribing information (2009) Princeton NJ: Bristol-Myers Squibb.

9. Glucophage $500 \mathrm{mg}$ and $850 \mathrm{mg}$ film coated tablets (2010) Summary of Product Characteristics (SPC). Merck Serono.

10. Wright EM, Loo DD, Hirayama BA (2011) Biology of human sodium glucose transporters. Physiol Rev 91: 733-94.

11. Jurczak MJ, Lee HY, Birkenfeld AL, Jornayvaz FR, Frederick DW, et al. (2011) SGLT2 deletion improves glucose homeostasis and preserves pancreatic betacell function. Diabetes 60: 890-898.

12. Bakris GL, Fonseca VA, Sharma K, Wright EM (2009) Renal sodium-glucose transport: role in diabetes mellitus and potential clinical implications. Kidney Int 75: $1272-1277$.

13. Wright EM, Hirayama BA, Loo DF (2007) Active sugar transport in health and disease. J Intern Med 261: 32-43.

14. Lamos EM, Younk LM, Davis SN. (2013) Canagliflozin , an inhibitor of sodiumglucose cotransporter 2, for the treatment of type 2 diabetes mellitus. Expert Opin Drug MetabToxicol 9: 763-775.

15. Liang Y, Arakawa K, Ueta K, Matsushita Y, Kuriyama C, et al. (2012) Effect of canagliflozin on renal threshold for glucose, glycemia, and body weight in normal and diabetic animal models. PLoS One 7.

16. Macdonald FR, Peel JE, Jones HB, Mayers RM, Westgate L, et al. (2010) The novel sodium glucose transporter 2 inhibitor dapagliflozin sustains pancreatic function and preserves islet morphology in obese, diabetic rats. Diabetes ObesMetab 12: 1004-1012.

17. Nomura S, Sakamaki S, Hongu M, Kawanishi E, Koga Y, et al. (2010) Discovery of canagliflozin, a novel C-glucoside with thiophene ring, as sodium-dependent glucose cotransporter 2 inhibitor for the treatment of type 2 diabetes mellitus. J Med Chem 53: 6355-6360.

18. Sha S, Devineni D, Ghosh A, Polidori D, Chien S, et al. (2011) Canagliflozin, a novel inhibitor of sodium glucose co-transporter 2 , dose dependently reduces calculated renal threshold for glucose excretion and increases urinary glucose excretion in healthy subjects. Diabetes ObesMetab 13: 669-672.

19. Neumiller JJ, White JRJr, Campbell RK (2010) Sodium-glucose co-transport inhibitors: progress and therapeutic potential in type 2 diabetes mellitus. Drugs. 70: 377-385

20. Polidori D, Sha S, Mudaliar S, Ciaraldi TP, Ghosh A, et al. (2013) Canagliflozin lowers postprandial glucose and insulin by delaying intestinal glucose 
Citation: Devineni D, Curtin CR, Ariyawansa J, Weiner S, Stieltjes H, et al. (2014) Bioequivalence of Canagliflozin/Metformin Immediate Release Fixed-Dose Combination Tablets Compared with Concomitant Administration of Single Components of Canagliflozin and Metformin in Healthy Fed Participants. J Bioequiv Availab 6: 164-173. doi:10.4172/jbb.1000199

absorption in addition to increasing urinary glucose excretion: results of a randomized, placebo-controlled study. Diabetes Care. 36: 2154-2161.

21. Canagliflozin (Invokana ${ }^{\mathrm{TM}}$ ) Prescribing Information. (2013) Titusville, NJ: Janssen Pharmaceuticals, Inc. 2013.

22. Canagliflozin (Invokana ${ }^{\mathrm{TM}}$ ) Summary of Product Characteristics. Beerse, Belgium: Janssen-Cilag International NV. 2013

23. Elkinson S, Scott LJ (2013) Canagliflozin: first global approval. Drugs 73: 979 988.

24. Forst T, Guthrie R, Goldenberg R, Yee J, Vijapurkar U, et al. (2014) Efficacy and safety of canagliflozin over 52 weeks in patients with type 2 diabetes on background metformin and pioglitazone. Diabetes ObesMetab 16: 467-477.

25. Lavalle-Gonzalez FJ, Januszewicz A, Davidson J, Tong C, Qu R, et al. (2013) Efficacy and safety of canagliflozin compared with placebo and sitagliptin in patients with type 2 diabetes on background metformin monotherapy: a randomised trial. Diabetologia. 56: 2582-2592.

26. Wilding JP, Charpentier G, Hollander P, Gonzalez-Galvez G, Mathieu C, et al. (2013) Efficacy and safety of canagliflozin in patients with type 2 diabetes mellitus inadequately controlled with metformin and sulphonylurea: a randomised trial. Int J ClinPract 67: 1267-1282.

27. Bangalore S, Kamalakkannan G, Parkar S, Messerli FH (2007) Fixed-dose combinations improve medication compliance: a meta-analysis. Am J Med. 120: 713-719.

28. Benford M, Milligan G, Pike J, Anderson P, Piercy J, et al. (2012) Fixed-dose combination antidiabetic therapy: real-world factors associated with prescribing choices and relationship with patient satisfaction and compliance. AdvTher 29: $26-40$

29. http://ec.europa.eu/health/documents/community-register/html/newproc. htm\#h.

30. h t t p : / / w w w. f d a.g o v / d o w n I o a d s / D r u g s / GuidanceComplianceRegulatoryInformation/Guidances/UCM070124.pdf
31. Viswanathan C, Bansal S, Booth B, DeStefano AJ, Rose MJ, et al. (2007) Workshop/conference report-Quantitative bioanalytical methods validation and implementation: Best practices for chromatographic and ligand binding assays. The AAPS Journal 9: E30-E42.

32. http://www.fda.gov/downloads/Drugs/Guidances/ucm070107.pdf.

33. Cefalu WT, Leiter LA, Yoon KH, Arias P, Niskanen L, et al. (2013) Efficacy and safety of canagliflozin versus glimepiride in patients with type 2 diabetes inadequately controlled with metformin (CANTATA-SU): 52 week results from a randomised, double-blind, phase 3 non-inferiority trial. Lancet. 382: 941-950.

34. Schernthaner G, Gross JL, Rosenstock J, Guarisco M, Fu M, et al. (2013) Canagliflozin compared with sitagliptin for patients with type 2 diabetes who do not have adequate glycemic control with metformin plus sulfonylurea: a 52 week randomized trial. Diabetes care 36: 2508-2515.

35. Devineni D, Manitpisitkul P, Murphy J, Skee D, Wajs E, et al. (2014) Effect of canagliflozin on the pharmacokinetics of glyburide, metformin and simvastatin in healthy participants. Clinical Pharmacology in Drug Development.

36. Devineni D, Manitpisitkul P, Murphy J, Stieltjes H, Ariyawansa J (2014) Effect of food on the pharmacokinetics of canagliflozin, a sodium glucose co-transporter 2 inhibitor, and assessment of dose proportionality in healthy participants. Clinical Pharmacology in Drug Development.

37. Devineni D, Curtin CR, Polidori D, Gutierrez MJ, Murphy J, et al. (2013) Pharmacokinetics and Pharmacodynamics of Canagliflozin, a Sodium Glucose Co-Transporter 2 Inhibitor, in Subjects with Type 2 Diabetes Mellitus. J ClinPharmacol 53: 601-610.

38. Devineni D, Vaccaro N, Polidori D, Curtin C, Stielties H, et al. (In Press2014) Single and multiple dose pharmacokinetics and pharmacodynamics of canagliflozin, a selective inhibitor of sodium-glucose co-transporter 2 , in healthy participants. Int J Clin Pharm Th.

39. Scheen AJ (1996) Clinical pharmacokinetics of metformin.Clin Pharmacokinet 30: $359-71$. 